\title{
O ACESSO À INFORMAÇÃO AMBIENTAL E A GESTÃO HÍDRICA: UMA ANÁLISE DA IMPLEMENTAÇÃO DO SISTEMA NACIONAL DE INFORMAÇÕES SOBRE RECURSOS HÍDRICOS (SNIRH) ${ }^{12}$
}

\author{
João Vitor Rodrigues Martins ${ }^{3}$
}

\begin{abstract}
RESUMO
O presente artigo realiza uma análise da implementação do Sistema Nacional de Informações de Recursos Hídricos (SNIRH), tendo como foco os gestores públicos responsáveis pela sua elaboração e manutenção e os representantes da sociedade civil presentes no Conselho Nacional de Recursos Hídricos (CNRH), responsável pelo gerenciamento da Política Nacional de Recursos Hídricos, como aponta a Lei das Águas. Discutindo inicialmente a construção do debate sobre a informação ambiental enquanto ferramenta de participação democrática e como concretização do direito fundamental ao meio ambiente, o acesso a tais informações é apontado enquanto forma de possibilitar o controle participativo na gestão hídrica. Por fim, o trabalho apresenta os resultados de uma análise qualitativa de redes sociais a partir de dados extraídos das atas das reuniões ordinárias e extraordinárias do CNRH entre 2006 e 2016 e de questionários eletrônicos respondidos pelos conselheiros, entre eles estão a avaliação do caráter marginal conferido ao tema do acesso à informação na gestão hídrica nacional e a necessidade de que seja atribuída uma maior centralidade ao SNIRH.
\end{abstract}

Palavras-chave: Gestão hídrica. Direito à informação. Análise de redes sociais. Informação ambiental.

\begin{abstract}
This article analyzes the implementation of the Sistema Nacional de Informações de Recursos Hídricos (SNIRH), focusing on the policymakers responsible for its elaboration and maintenance and the representatives of civil society present at the Conselho Nacional de Recursos Hídricos (CNRH), responsible for the management of the Política Nacional de Recursos Hídricos, as pointed out in the Lei das Águas. Discussing initially the construction of the debate on environmental information as a tool for democratic participation and as a materialization of the fundamental right to the environment, the access is pointed out as a way to enable participatory control in water management. Finally, the paper presents the results of a qualitative analysis of social networks based on data extracted from the minutes of the ordinary and extraordinary meetings of the CNRH between 2006 and 2016 and of electronic questionnaires answered by the counselors, seeking to organize an interpretation on how access to information is dealt within such a policy network, among them are the evaluation of the marginal character conferred to the theme of access to information and the need for a greater centrality to the SNIRH.
\end{abstract}

Keywords: Water management. Right to information. Social network analysis. Environmental information.

\section{RESUMEN}

El artículo realiza un análisis de la implementación del Sistema Nacional de Informações de Recursos Hídricos (SNIRH), teniendo como foco a los gestores públicos responsables por su elaboración y mantenimiento y los representantes de la sociedad civil presentes en el Conselho Nacional de Recursos Hídricos (CNRH), responsable por la gestión de la Política Nacional de Recursos Hídricos, como señala la Lei das Águas. Discutiendo inicialmente la construcción del debate sobre la información ambiental como herramienta de participación democrática y como concreción del derecho fundamental al medio ambiente, el acceso es señalado como forma de posibilitar el control participativo en la gestión hídrica. Por último, el trabajo presenta los resultados de un análisis cualitativo de redes sociales a partir de datos extraídos de las actas de las reuniones ordinarias y extraordinarias del CNRH entre 2006 y 2016 y de cuestionarios electrónicos respondidos por los consejeros, buscando organizar una interpretación sobre cómo el acceso a la información se trata de una red de políticas, entre ellos están la evaluación del carácter marginal conferido al tema del acceso a la información en la gestión hídrica nacional y la necesidad de que se atribuya una mayor centralidad al SNIRH. Palabras clave: Gestión hídrica. Derecho a la información. Análisis de redes sociales. Información ambiental.

\footnotetext{
${ }^{1}$ Submetido em: 30 de Setembro de 2017. Aprovado em: 15 de Outubro de 2017.

${ }^{2}$ DOI: http://dx.doi.org/10.5380/recp.v8i3.57153

${ }^{3}$ Graduando do $7^{\circ}$ semestre em Ciência Política pelo Instituto de Ciência Política da Universidade de Brasília, extensionista pelo Projeto Universitários Vão à Escola, membro do Programa de Educação Tutorial (PET) em Ciência Política e do Grupo de Pesquisa e Observatório em Políticas Públicas (GEOPP). E-mail: joaovitormartins2@gmail.com.
} 


\section{INTRODUÇÃO}

A presente pesquisa busca compreender o processo de implementação do direito de acesso à informação na gestão de águas a partir do Sistema Nacional de Informações Sobre Recursos Hídricos (SNIRH), como ferramenta de disponibilização de dados, e do Conselho Nacional de Recursos Hídricos (CNRH), como instância de controle democrático participativo na gestão hídrica.

Ao entender a caracterização da informação e da liberdade de expressão como partes do rol de direitos humanos fundamentais para a construção de um estado democrático de direito, o trabalho utiliza uma articulação entre o debate sobre democracia participativa e o direito à informação para pensar os mecanismos de controle da gestão da política hídrica no Brasil.

A estrutura do artigo é composta de três pontos principais, além desta introdução e dos argumentos conclusivos apresentados na sua última parte. Inicialmente, trata-se da contextualização do processo de reconhecimento do direito à informação enquanto um direito fundamental e, posteriormente, do acesso à informação ambiental como parte integrante de uma política ambiental internacional. Aborda-se, posteriormente, como tais princípios são articulados na construção da gestão de recursos hídricos no Brasil, apresentando-se seus marcos legais e a estruturação dos dois meios de análise utilizados, o SNIRH e o CNRH. No último tópico do texto, a análise de redes sociais é utilizada para pensar a atuação dos atores políticos, sejam gestores ou organizações civis, envolvidos na concretização do direito de acesso à informação em matéria hídrica.

\section{DIREITO À INFORMAÇÃO AMBIENTAL}

\section{1 A CONSTRUÇÃO DO RECONHECIMENTO JURÍDICO-CONSTITUCIONAL DO DIREITO À INFORMAÇÃO}

O direito à informação foi construído, ao longo do tempo, como um princípio a ser respeitado em regimes democráticos e, principalmente, como um direito humano fundamental. Podendo ser tratado como uma derivação do direito à liberdade de expressão, a informação vem ganhando papel central no exercício das funções da administração pública e no processo de controle, pelos cidadãos e pelas organizações da sociedade civil, da gestão governamental. 
MARTINS, J. V. R. O acesso à informação ambiental e a gestão hídrica: uma análise da implementação do sistema nacional...

O processo de consolidação de tal direito na esfera internacional passou por diferentes fases e momentos. É possível destacar algumas resoluções, tratados e declarações internacionais que fortaleceram o esforço coletivo para o reconhecimento do direito à informação como parte constituinte do rol de garantias democráticas. Dentre eles, Oliveira, Dinarte e Silva (2014) destacam três documentos centrais para o entendimento de que todo cidadão possui o direito da circulação livre de informações, sem pressupostos restritivos quanto aos instrumentos para tal comunicação: a Declaração Universal dos Direitos Humanos, de 1948; o Pacto Internacional sobre Direitos Civis e Políticos, de 1966, que foi internalizado no ordenamento jurídico brasileiro pelo Decreto ${ }^{\circ}$ 592, em 1992; e a Convenção Americana sobre Direitos Humanos, que foi assinada em San José, na Costa Rica, em 1969, e internalizada no Brasil por meio do Decreto Presidencial no 678, em 1992.

Ainda na esfera internacional, podem ser apresentados dois outros marcos nesse sentido. Primeiramente, a Declaração de Princípios sobre Liberdade de Expressão da Organização dos Estados Americanos, que representa um reconhecimento do bloco americano dos princípios formados em escalas multilaterais sobre a liberdade de expressão, dentre os quais destacam-se a inalienabilidade da liberdade de expressão; o direito de acesso a informações pessoais (mesmo que em posse da administração pública); o caráter fundamental do direito de acesso à informação em poder do Estado; e a noção de impossibilidade de restrição da difusão de informação de interesse público enquanto regra geral, retirando-se o pressuposto do acesso como exceção (ORGANIZAÇÃO DOS ESTADOS AMERICANOS, 2000).

Em segundo lugar, especificamente sobre o tema do acesso, temos os Princípios de Acesso aos Arquivos, pensados pelo Conselho Internacional de Arquivos, em 2011, que destacam ideias como o direito de acesso aos arquivos de órgãos públicos pelo público em geral; a disponibilidade dos documentos ao público; e a ideia de que os arquivos precisam ser pensados para assegurar a preservação e o acesso aos documentos em sua posse (CONSELHO INTERNACIONAL DE ARQUIVOS, 2011).

Na ordem constitucional brasileira, temos a proteção ao direito à informação garantida pelos incisos XIV e XXXIII do artigo $5^{\circ}$ e pelo artigo 37 da Constituição de 1988, com menções diretas à necessidade da ampla disponibilização dos documentos e das informações pela administração pública (BRASIL, 1988). Em termos recentes, é possível destacar, também, as importantes conquistas representadas pela aprovação da Lei de Acesso à Informação (LAI), Lei $\mathrm{n}^{\mathrm{o}}$ 12.527, de 2011, buscando regulamentar os dispositivos constitucionais que tratam do acesso à informação (BRASIL, 2011). A lei possui aplicabilidade ampla, abrangendo os três poderes da União nas três esferas federativas (União, estados, Distrito Federal e municípios), 
estimulando, assim, uma "cultura de acesso" à informação como base de um processo de controle coletivo da administração pública (OLIVEIRA; DINARTE; SILVA, 2014).

A LAI foi construída segundo parâmetros internacionais desenvolvidos conjuntamente a partir de comparações de diferentes marcos legais sobre a liberdade de informação. Faz-se necessário destacar o papel de articulação desenvolvido pela organização não governamental Artigo 19 no estabelecimento desses arranjos institucionais. Partindo da noção de que a informação é necessária para a contribuição coletiva e participativa e essencial para a boa governança, a organização orienta seu trabalho a partir de princípios como a máxima divulgação; a obrigação da administração pública de publicar informação; e a necessidade de regras claras e objetivas a respeito das informações submetidas à exceção de publicação (ARTIGO 19, 1999).

Ao retirar da discricionariedade administrativa o poder de decisão sobre a disponibilização ou não de informações, os princípios trabalhados orientam uma visão que pressupõe abrangência máxima das informações a serem divulgadas e das pessoas que podem acessá-las, ideia a ser afastada somente quando há considerável dano a um interesse público ou a um direito privado legítimo (MENDEL, 2009).

\subsection{O DIREITO À INFORMAÇÃO ENQUANTO FERRAMENTA DEMOCRÁTICA PARTICIPATIVA EM UM CONTEXTO DE GLOBALIZAÇÃO}

A informação é central para o processo de controle da gestão pública pelo cidadão, já que o acesso a dados sobre a atuação da administração pública fornece meios de qualificação e avaliação do gerenciamento de diferentes programas governamentais. Nesse sentido o direito ganha contornos de mecanismo de desenvolvimento de participação democrática. As políticas de acesso à informação, assim, adquirem importante função e relevância, necessitando de formulações que levem em consideração as dificuldades, sejam linguísticas, técnicas e visuais, que as plataformas de veiculação desses dados possam apresentar (ROVER, 2006).

Em um contexto de difusão das tecnologias de informação, a internet passa a ser um ambiente primordial no processo de publicização democrática das informações da administração pública. O cibercidadão apresenta, nesse contexto, novas demandas em termos de consumo, acesso, veiculação e reutilização dos dados a que têm direito. Dessa forma,

Constata-se que fornecer os dados públicos no formato aberto oportuniza a reutilização, recombinação e o acesso às informações, também propicia o fortalecimento da democracia e participação cidadã. Isso é, os dados abertos 
MARTINS, J. V. R. O acesso à informação ambiental e a gestão hídrica: uma análise da implementação do sistema nacional...

governamentais são os dados produzidos pela administração pública e colocados à disposição das pessoas com o objetivo de tornar possível não apenas sua leitura, mas também a reutilização desses dados em novos projetos, plataformas, sites e aplicativos, seu cruzamento com outros dados de diferentes fontes, e sua disposição em visualizações interessantes e esclarecedoras sobre nossa sociedade (VAZ; RIBEIRO; MATHEUS, 2010, p. 46).

Tal desenvolvimento do debate sobre procedimentos para assegurar uma efetividade do direito à informação desenhou, conforme diversos apontamentos nos mostram, um formato institucional de Open Government, ou "Governo Aberto". Considerado central para o desenvolvimento democrático da participação cidadã, o debate internacional sobre a estrutura de um Governo Aberto pode ser sintetizado pelos princípios veiculados pela ONG Open Government Partnership, com iniciativas de formulação de programas em diversos países, inclusive no Brasil. É possível destacar, dentre tais princípios, a transparência das decisões governamentais, a promoção dos princípios democráticos e a efetiva intervenção dos cidadãos nos processos de definição de políticas de gestão a partir das informações disponibilizadas (OPEN GOVERNMENT PARTNERSHIP, 2016).

\subsection{DIREITO À INFORMAÇÃO AMBIENTAL COMO INTERSECÇÃO ENTRE O ACESSO À INFORMAÇÃO E A GARANTIA DO DIREITO FUNDAMENTAL AO MEIO AMBIENTE}

Partindo das construções do direito à informação, pela ótica do seu reconhecimento constitucional como direito humano fundamental e pelo debate de sua importância para a configuração de uma participação democrática direta, o direito à informação ambiental ganha importante papel na concretização do princípio do direito a um meio ambiente ecologicamente equilibrado enquanto um direito difuso.

Para a formação de uma consciência coletiva sobre a preservação do meio ambiente e para o controle da gestão ambiental por parte do Estado, a informação foi elencada como um dos eixos essenciais de atuação de uma política governamental, pelo texto resultado da "Convenção sobre acesso à informação, participação do público no processo de tomada de decisões e acesso à justiça em matéria de ambiente", denominada "Convenção de Aarhus", em 1998 (AARHUS, 1998). 
Além disso, o acesso à informação é considerado aspecto fundamental no combate aos danos ambientais e na construção de uma relação saudável entre seres humanos e meio ambiente em diferentes documentos internacionais ${ }^{4}$, paradigmas da política ambiental internacional.

Enquanto princípio da política ambiental internacional, o acesso à informação ambiental, portanto, apresenta-se como ferramenta multifuncional, possibilitando o controle, a participação e a educação sobre o meio ambiente. A questão, então, é posta como um desafio a ser concretizado na forma de políticas públicas, levando-se em consideração as diversas complexificações que a temática traz, sejam elas administrativas, legais ou democráticas.

\section{A IMPLEMENTAÇÃO DE UMA POLÍTICA PÚBLICA DE ACESSO À INFORMAÇÃO EM RECURSOS HÍDRICOS E A PARTICIPAÇÃO E CONTROLE DEMOCRÁTICOS NESSE PROCESSO}

\subsection{O SISTEMA NACIONAL DE INFORMAÇÕES SOBRE RECURSOS HÍDRICOS ENQUANTO EXPRESSÃO DO DIREITO À INFORMAÇÃO DENTRO DA PNRH}

A Lei de Águas, Lei n ${ }^{\circ}$ 9.433, de 8 de janeiro de 1997, instituiu a Política Nacional de Recursos Hídricos (PNRH), adotando, no inciso VI do seu artigo $5^{\circ}$, o SNIRH como um de seus instrumentos de gestão (BRASIL, 1997). O texto legal aponta as bacias hidrográficas como unidade territorial da política hídrica, a partir do reconhecimento da autonomia federativa de gestão territorial por parte de estados e municípios (CEDRAZ, 2006).

No âmbito da participação democrática, a Lei das Águas representa um avanço na forma como a gestão de águas é pensada, já que atribui papel central aos Conselhos de Bacias Hidrográficas e aos Conselhos Estaduais de Recursos Hídricos (VIANA; PINHEIRO, 2015). Ao reconhecer a importância de tais instâncias de tomada de decisões no que diz respeito aos interesses coletivos, a PNRH passa a assegurar a ação direta de usuários de recursos hídricos e de representantes de segmentos da sociedade, uma visão inovadora na forma como um bem de domínio público é gerenciado pelo governo e pelas forças atribuídas à gestão compartilhada e ao controle social (ROMANO, E; ROMANO, P. A.; FEITOSA, 2006).

\footnotetext{
${ }^{4}$ Destacam-se a Declaração de Estocolmo sobre o Ambiente Humano, assinada na Conferência das Nações Unidas sobre o Meio Ambiente, em 1972 (ORGANIZAÇÃO DAS NAÇÕES UNIDAS, 1972), e a Declaração do Rio sobre Meio Ambiente e Desenvolvimento, apresentada no encontro conhecido como "RIO 1992" (ORGANIZAÇÃO DAS NAÇÕES UNIDAS, 1992).
} 
MARTINS, J. V. R. O acesso à informação ambiental e a gestão hídrica: uma análise da implementação do sistema nacional...

A própria inclusão do Sistema como um dos instrumentos de gestão da política hídrica é resultado da avaliação da dependência de informações e ferramentas analíticas de qualidade para a efetividade da participação pública na tomada de decisões e nas suas implementações (PORTO, M. F. A.; PORTO, R. L. L., 2008). Assim, em princípios expressos no texto legal, o SNIRH se constitui como um "um sistema de coleta, tratamento, armazenamento e recuperação de informações sobre recursos hídricos e fatores intervenientes em sua gestão", baseado em noções de: 1) descentralização da obtenção e produção de dados e informações; 2) coordenação unificada do sistema; e 3) acesso aos dados e informações garantido a toda a sociedade (BRASIL, 1997).

A implementação de uma política pública de acesso à informação, entretanto, possui inúmeros desafios, como os representados pelas barreiras administrativas de coleta e sistematização de informações e pelas dificuldades tecnológicas e informacionais relativas à democratização dos meios de divulgação. Para serem efetivas, a gestão e a administração do Sistema necessitam de uma estratégia sólida, com a coordenação de ações para barrar o comportamento usual de negação de informações solicitadas por parte dos órgãos públicos, mas também, para estimular o acesso aos espaços plurais de obtenção de dados (BARRETO, 2004). A complexidade do tema permite concluir que

\begin{abstract}
Em última análise, o processo de gestão exige ferramentas computacionais que permitam o acesso rápido aos dados da bacia hidrográfica, a avaliação de cenários atuais e futuros e a análise de alternativas de implantação de obras e/ou de operação de sistemas. Tomadas de decisão sobre outorga, eventuais racionamentos, enquadramento de cursos de água por classes de uso, controle de cheias, tratamento e diluição de efluentes, adoção de medidas de contingência e outras não podem prescindir de bases de informações sistematicamente organizadas e atualizadas. (VIANA; PINHEIRO, 2015, p. 69).
\end{abstract}

\title{
3.2 O CNRH ENQUANTO INSTÂNCIA DE REPRESENTAÇÃO DEMOCRÁTICA NO CONTROLE DO SNIRH
}

O Conselho Nacional de Recursos Hídricos (CNRH) desenvolve suas atividades desde 1998, sendo previsto como a instância hierarquicamente mais alta do Sistema Nacional de Gerenciamento de Recursos Hídricos, conforme a Lei das Águas (BRASIL, 1997). O Conselho, atualmente, é regido pela Portaria $n^{\circ} 437$, de 8 de novembro de 2013, contando com representações do governo federal, dos Conselhos Estaduais de Recursos Hídricos, dos usuários de recursos hídricos e de organizações civis de recursos hídricos. Configura-se como uma entidade portadora de diversidade representativa que abarca os diferentes grupos que se 
relacionam com a gestão hídrica, o CNRH ainda possui legitimidade democrática na promoção e definição da Política Nacional de Recursos Hídricos, a partir das moções (tratadas como recomendações ao Poder Público ou à sociedade civil), das resoluções (com amplitude nacional na definição das ações nos estados, municípios e bacias hidrográficas) e da aprovação das "Prioridades, ações e metas do Plano Nacional de Recursos Hídricos" de maneira quinquenal (BRASIL, 1997, 2013).

A literatura sobre os conselhos nacionais os consideram decorrentes de uma movimentação de ampliação da participação democrática na gestão pública, configurando-se como um "instrumento de diálogo, de discussão e de formulação de diretrizes para a elaboração de políticas públicas” (AVRITZER, 2010, p. 28). Assegurando uma maior interação do Estado com a sociedade, a formação de conselhos permite o estabelecimento de arenas que incluam sujeitos excluídos dos processos de tomada de decisão referentes às políticas públicas (AVRITZER; SOUZA, 2013).

Em termos de discussão sobre o direito à informação, o CNRH possui a Câmara Técnica de Educação e Informação em Recursos Hídricos, com resoluções e moções aprovadas que abordam a importância da supervisão do SNIRH. Entre este rol de documentos, é possível destacar a Resolução $\mathrm{n}^{\circ} 13$, de 25 de setembro de 2000, que estabelece diretrizes para a implementação do SNIRH a partir de determinações de ações da Agência Nacional de Águas (ANA), responsável pela gestão do Sistema de acordo com a Lei de Águas. Há um reforço da necessidade de a ANA promover esforços interinstitucionais para o fortalecimento da gestão integrada de águas e para a melhoria dos procedimentos de produção, consolidação e disponibilização das informações sobre tais ações. Assim, a Câmara Técnica consolida a necessidade de integração e coordenação entre os próprios órgãos gestores dos sistemas de informação para o cruzamento e compartilhamento de dados e mecanismos de veiculação (BRASIL, 1997, 2000).

\section{ANÁliSE dA ATUAÇÃO DA REDE POLÍTICA CONSTITUÍDA NO ÂMBITO DO CNRH NO CONTROLE DE QUALIDADE DA IMPLEMENTAÇÃO DO SNIRH}

\subsection{METODOLOGIA DE ANÁLISE DE REDES SOCIAIS}

Neste tópico, o trabalho busca analisar as discussões sobre o direito à informação na gestão de recursos hídricos a partir da experiência do conjunto de atores do Conselho Nacional de Recursos Hídricos, enquanto uma rede de políticas. Para entender as relações entre os órgãos 
MARTINS, J. V. R. O acesso à informação ambiental e a gestão hídrica: uma análise da implementação do sistema nacional...

e as entidades engajadas na construção dessa esfera decisória, duas ferramentas foram utilizadas: a análise das atas das reuniões do Conselho, por meio das notas taquigráficas disponibilizadas em seu endereço eletrônico, e um questionário enviado aos atuais conselheiros, veiculado e respondido por via eletrônica.

Tais instrumentos serão abordados em detalhe posteriormente, assim como suas interpretações. Porém, é preciso contextualizar a metodologia de redes sociais utilizada no presente estudo, dentro da perspectiva teórica de redes de política.

Os estudos das redes sociais surgem como uma abordagem teórica e metodológica que busca uma resposta diante das dicotomias apresentadas pelas Ciências Sociais — até então, entre as visões micro e macrossociológicas das relações entre indivíduo e sociedade (EMIRBAYER; GOODWIN, 1994). Tal campo se desenvolveu a partir, principalmente, das ideias de Durkheim sobre a construção da solidariedade orgânica por meio dos padrões supraindividuais das relações sociais. A rede social, nesse contexto, representaria uma forma de configuração das relações sociais por meio de contextos específicos, com padrões de laços, conexões e aproximações entre os agentes que a compõem (BOORMAN; WHITE, 1976).

Aplicada ao contexto da gestão de políticas públicas, tal visão permite entender como os comportamentos dos atores resultam de relações estruturadas em padrões coletivos, e não somente de atributos, valores e normas individuais ou exclusivos. Além disso, há o entendimento de que as atitudes dos atores podem ser melhor previstas e analisadas quando vistas por meio das relações em rede em que estão inseridas, já que as decisões tomadas por eles não dependem exclusivamente de negociações e construções isoladas, mas são influenciadas por todos os pares presentes na sua teia de relações (WELLMAN, 1983). O objeto deste artigo, portanto, passa a ser o grupo ou a rede de políticas públicas, e não o processo de formação e delimitação da agenda de atores individuais (BOORMAN; WHITE, 1976).

O conceito de "rede", portanto, é considerado uma alternativa aos modelos pluralistas e neocorporativistas, que, respectivamente, trabalham com perspectivas muito abertas e muito fechadas em relação à possibilidade de os atores políticos envolvidos nos processos das políticas públicas terem acesso aos recursos do Estado, em um sistema de concorrência aberta, no primeiro, ou fechada, no segundo (MASSARDIER, 2006). Marques (2003), então, utiliza o processo de constituição de redes enquanto uma metodologia de estudo de gestão de políticas como uma alternativa aos modelos inflexíveis representados por estruturas hierárquicas. A visão proposta pelo autor parte de uma concepção dos atores enquanto agentes interdependentes que compartilham valores de troca, interação e corresponsabilidade dentro de uma mesma rede. 
As redes, então, funcionam como instituições com dinâmicas próprias, capazes de construir comportamentos, gerenciar conflitos e fornecer incentivos por meio de sua atuação previsível e generalizada. Em sentido geral,

[...] o efeito das instituições políticas e das redes sobre a dinâmica social se assemelham, já que ambas estruturam os ambientes onde os processos políticos se dão. [...] Para os neoinstitucionalistas, especialmente os históricos, as instituições agiriam como molduras da política e das políticas, não apenas influenciando resultados, mas alterando as próprias preferências dos atores ao definir possibilidades e probabilidades para diferentes estratégias, alianças e linhas de ação (STEINMO et al., 1992). De forma similar, as redes influenciam resultados dos processos políticos, assim como alteram estratégias e mesmo preferências de atores e grupos. Essa influência não é mutuamente exclusiva, mas, ao contrário, ocorre de forma concomitante e paralela. (MARQUES, 2003, p. 191).

A ferramenta usual para a representação visual das redes sociais é o sociograma, como uma demonstração de todos os pontos (representando os atores) e nós (as relações entre os atores) coletados na pesquisa. A construção gráfica é centrada na descrição espacial das relações entre os atores segundo medidas de coesão, densidade e centralidade, entre outras (SCOTT, 2000).

Os sociogramas apresentados a seguir foram concebidos de acordo com dois modelos complementares. Inicialmente, Wasserman e Faust tomam como elementos fundamentais da análise e da construção gráfica das redes os seguintes elementos: os nós (polos que integram a rede), posições (que definem a localização dos nós nas redes), as ligações (as conexões que determinam o grau de densidade dos atores nas redes) e os fluxos (movimentos de troca de recursos, informações e contatos, representados pelas linhas que conectam os nós). A interpretação das redes deve se basear em seus aspectos estruturais (medidas de centralidade, densidade e coesão), posicionais (análise de equivalência estrutural e de regularidade) e relacionais (testando proposições teóricas sobre as conexões entre os atores) (WASSERMAN; FAUST, 1994).

Katz et al., posteriormente, conceituam rede como um conjunto de atores, que podem ser indivíduos, grupos ou organizações, representados pelos pontos gráficos, e as relações entre eles. As ligações podem se diferenciar de acordo com a maneira como as conexões são estabelecidas, com o conteúdo (se são relações políticas, econômicas, afetivas, etc.), com a reciprocidade, com a frequência e com a média, entre outros fatores. Segundo essa linha metodológica, são propostas cinco observações fundamentais no estudo de redes sociais: que o comportamento de um ator é melhor explicado pela rede de relacionamentos a que ele está submetido do que por seus atributos e valores individuais; que o foco do estudo é o 
MARTINS, J. V. R. O acesso à informação ambiental e a gestão hídrica: uma análise da implementação do sistema nacional...

relacionamento entre as unidades da rede, e não a relação entre os atores separadamente; que se pode presumir a interdependência entre os atores; que o fluxo de informação e recurso entre os atores não depende somente da relação entre eles, mas sim do relacionamento entre todos os outros atores; e que as fronteiras entre as redes não são claras (KATZ et al., 2004).

Tais definições e preceitos foram a base metodológica para a coleta e a interpretação dos dados referentes à forma como o direito à informação e a sua concretização em políticas, dentro da questão hídrica, são tratados pelos gestores e pelos atores da sociedade civil presentes no CNRH.

\subsection{RESULTADO DA ANÁLISE DAS NOTAS TAQUIGRÁFICAS DAS REUNIÕES DO $\mathrm{CNRH}$}

Para a avaliação de como o direito à informação e, mais especificamente, o Sistema Nacional de Recursos Hídricos foram tratados nas discussões entre os conselheiros, utilizou-se a análise das atas das reuniões ordinárias e extraordinárias do Conselho Nacional de Recursos Hídricos. O levantamento se baseou nas atas de 14 reuniões ordinárias e 12 reuniões extraordinárias do Conselho, no período de 31 de janeiro de 2006 a 8 de dezembro de 2016, data da última reunião realizada.

O estudo das notas taquigráficas observou, quanto ao tema pesquisado, a abordagem por quatro eixos centrais de discussão: o próprio direito à informação e suas implicações para a gestão de recursos hídricos, o funcionamento e a aplicabilidade do SNIRH, a gestão do Sistema Nacional de Informações sobre Segurança de Barragens e a gestão do Sistema Nacional de Informações sobre Saneamento. ${ }^{5}$ Os eixos podem, então, ser diferenciados de acordo com a frequência com que são mencionados nas discussões, já que representam, respectivamente, o ponto central de 76, 10, 8 e 2 discursos no total analisado.

Assim, o sociograma abaixo (Figura 1), construído utilizando a ferramenta yEd Graph Editor, oferece uma visualização dos dados obtidos:

\footnotetext{
${ }^{5}$ Os sistemas, embora não façam parte da estrutura do SNIRH, configuram-se como mecanismos de distribuição e acesso à informação de áreas correlatas à gestão de recursos hídricos e, portanto, estão presentes, também, nas discussões do Conselho sobre o tema. O Sistema Nacional de Informações sobre Seguranças de Barragens foi estabelecido pela Lei $\mathrm{n}^{\mathrm{o}}$ 12.334, de 20 de setembro de 2010, e o Sistema Nacional de Informações sobre Saneamento foi instaurado pela Lei $\mathrm{n}^{\circ} 11.445$, de 5 de janeiro de 2007.
} 


\section{FIGURA 1 - REDE DO CNRH A PARTIR DO EIXO DE DISCUSSÃO} DO DIREITO À INFORMAÇÃO

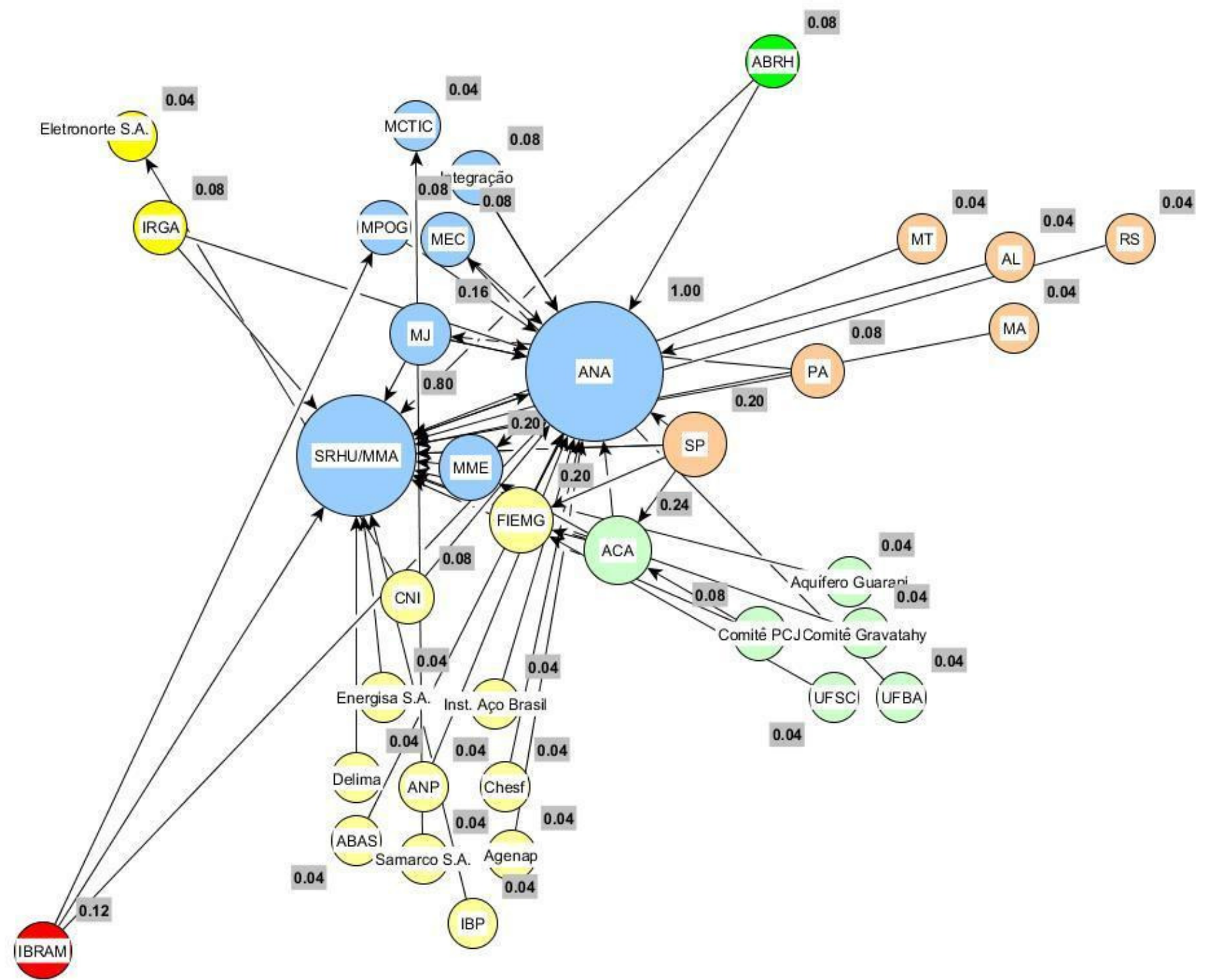

FONTE: O autor (2017).

Para a construção gráfica, utilizou-se uma distinção entre quatro grupos: representantes do Governo Federal (em azul-claro), dos Conselhos Estaduais de Recursos Hídricos (em laranja), dos usuários de recursos hídricos (em amarelo-claro) e de organizações civis de recursos hídricos (em verde-claro), seguindo-se a estrutura presente na Lei $n^{\circ}$ 9.433, de 1997 (BRASIL, 1997). Podemos concluir, então, que 35 atores (entre conselheiros e convidados) distintos participaram das discussões sobre o tema de estudo, demonstrados pela tabela ${ }^{6}$ a seguir.

\footnotetext{
${ }^{6} \mathrm{Na}$ Tabela 1, há a relação de todos os nós utilizados na rede, assim como o número respectivo referente ao grau de centralidade de acordo com a metodologia de análise de redes anteriormente comentada (KATZ et al., 2004), (WASSERMAN; FAUST, 1994).
} 
MARTINS, J. V. R. O acesso à informação ambiental e a gestão hídrica: uma análise da implementação do sistema nacional...

TABELA 1 - Dados de centralidade referentes à rede do CNRH a partir do eixo de discussão do direito à informação

\section{GOVERNO FEDERAL}

\begin{tabular}{|c|c|}
\hline \multicolumn{2}{|l|}{ GOVERNO FEDERAL } \\
\hline 1. Secretária Nacional de Recursos Hídricos e Qualidade Ambiental (SNRH/MMA) & 0.8 \\
\hline 2. $\quad$ Agência Nacional de Águas (ANA) & 1.0 \\
\hline 3. Ministério da Integração (Integração) & 0.08 \\
\hline 4. Ministério de Planejamento, Orçamento e Gestão (MPOG) & 0.08 \\
\hline 5. $\quad$ Ministério de Minas e Energia (MME) & 0.2 \\
\hline 6. $\quad$ Ministério da Justiça (MJ) & 0.16 \\
\hline 7. Ministério da Ciência, Tecnologia, Inovações e Comunicações (MCTIC) & 0.04 \\
\hline 8. Ministério da Educação (MEC) & 0.08 \\
\hline \multicolumn{2}{|l|}{ CONSELHOS ESTADUAIS } \\
\hline 1. Conselho Estadual de Recursos Hídricos do Mato Grosso (MS) & 0.04 \\
\hline 2. Conselho Estadual de Recursos Hídricos de São Paulo (SP) & 0.2 \\
\hline 3. Conselho Estadual de Recursos Hídricos do Rio Grande do Sul (RS) & 0.04 \\
\hline 4. Conselho Estadual de Recursos Hídricos do Maranhão (MA) & 0.04 \\
\hline 5. Conselho Estadual de Recursos Hídricos de Alagoas (AL) & 0.04 \\
\hline 6. Conselho Estadual de Recursos Hídricos do Pará (PA) & 0.16 \\
\hline \multicolumn{2}{|l|}{$\begin{array}{lll}\text { USUÁRIOS } \\
\end{array}$} \\
\hline 1. Confederação Nacional das Indústrias (CNI) & 0.08 \\
\hline 2. Samarco Mineração S.A. & 0.04 \\
\hline 3. Grupo Energisa S.A. & 0.04 \\
\hline 4. Eletronorte - Centrais Elétricas do Norte do Brasil S/A & 0.04 \\
\hline 5. Instituto Riograndense do Arroz - IRGA & 0.04 \\
\hline 6. Federação das Indústrias de Minas Gerais - FIEMG & 0.16 \\
\hline 7. Agência da Bacia do Rio Paraíba do Sul - AGEVAP & 0.04 \\
\hline 8. Companhia Hidrelétrica do São Francisco - Chesf & 0.04 \\
\hline 9. Instituto Brasília Ambiental - IBRAM & 0.12 \\
\hline 10. Agência Nacional do Petróleo - ANP & 0.04 \\
\hline 11. Delima Comércio e Navegação & 0.04 \\
\hline 12. Instituto Aço Brasil & 0.04 \\
\hline 13. Associação Brasileira de Águas Subterrâneas - ABAS & 0.04 \\
\hline 14. Instituto Brasileiro de Petróleo, Gás e Biocombustíveis - IBP & 0.04 \\
\hline \multicolumn{2}{|l|}{ ORGANIZAÇÕES CIVIS } \\
\hline 1. Associação Brasileira de Recursos Hídricos - ABRH & 0.08 \\
\hline 2. Associação Camponesa - ACA & 0.24 \\
\hline 3. Comitê Gravatahy & 0.04 \\
\hline 4. Comitê das Bacias Hidrográficas dos Rios Piracicaba, Capivari e Jundiaí (PCJ) & 0.04 \\
\hline 5. Projeto de Proteção Ambiental e Desenvolvimento Sustentável do Aquífero Guarani & 0.04 \\
\hline 6. Universidade Federal da Bahia - UFBA & 0.04 \\
\hline 7. Universidade Federal de Santa Catarina - UFSC & 0.04 \\
\hline
\end{tabular}

FONTE: O autor (2017).

Após a apresentação dessas informações iniciais, é possível construir uma interpretação do sociograma conforme a metodologia de redes supracitada. Os tamanhos dos nós foram delimitados a partir do cálculo de centralidade de acordo com o número de conexões estabelecidas dentro da rede. Assim, é possível construir uma escala de valores entre 0,04, representando apenas um discurso centrado na discussão sobre o direito à informação (já que o 
critério estabelecido para a construção gráfica parte da constatação de pelo menos uma menção ao tema nas falas da reunião), e 1, representando o número de 22 discursos. Com tal escala, é possível observar uma concentração alta em dois atores: a Agência Nacional de Águas (valor 1, na escala) e a Secretaria de Recursos Hídricos e Qualidade Ambiental (valor 0,8), representando, somados, $47 \%$ do total de discursos sobre o direito à informação e os sistemas nacionais de informação em recursos hídricos.

Esse papel pode ser explicado tanto pela importância desses órgãos dentro da estrutura do Conselho Nacional, possuindo grande influência de formação de agenda e de voz dentro das reuniões (o que pode ser exemplificado pelo considerável número de falas que eles apresentam), como pelas suas centralidades no que diz respeito ao tema do direito à informação — aspectos estes, também, advindos das atribuições e competências legais dos dois atores na gestão do Sistema Nacional de Recursos Hídricos e nos outros sistemas de informação, conforme a Lei de Águas (BRASIL, 1997).

Os nós que formam as periferias na rede do gráfico representam um grande número de atores que trazem o tema da informação sobre recursos hídricos de maneira pontual e, às vezes, marginal dentro de suas pautas. Por tal motivo, 26 dos 36 atores possuem somente uma ou duas falas que abordam tal temática (valores 0,04 e 0,08 na escala, respectivamente). Esse fato pode fornecer um instrumento, dentre outros fatores, para analisar como o direito à informação é tratado pelos gestores e membros da sociedade civil dentro do Conselho, já que tal direito aparenta ter uma baixa prioridade diante de outros assuntos recorrentes que contam com maior participação dos atores de uma forma geral.

Um último fator, referente aos temas marginais dentro do gráfico, precisa ser apresentado. Alguns atores fazem menções específicas a assuntos pouco abordados pelos outros gestores. O distanciamento conferido ao Ibram, à Eletronorte S.A., ao Irga e à ABRH busca retratar como essas entidades trouxeram à tona os temas de funcionamento do SNIRH (representado pelo nó verde), do Sistema Nacional de Informações sobre Saneamento (nós amarelos) e do Sistema Nacional de Informações sobre Seguranças de Barragens (nó vermelho). Esses atores, do grupo de usuários de recursos hídricos, saíram das discussões gerais sobre o direito à informação, cobrando uma ação mais organizada dos órgãos gestores dos sistemas para a maior efetividade na disponibilização das informações, apontando falhas, críticas e sugestões de melhoria no acesso aos dados. 
MARTINS, J. V. R. O acesso à informação ambiental e a gestão hídrica: uma análise da implementação do sistema nacional...

\subsection{RESULTADO DA ANÁLISE A PARTIR DAS RESPOSTAS DOS CONSELHEIROS AO FORMULÁRIO}

Além da leitura e avaliação das atas das reuniões do Conselho, utilizou-se como ferramenta de coleta de dados um formulário eletrônico enviado para os e-mails dos atuais conselheiros, conforme informações disponibilizadas no site do $\mathrm{CNRH}$. O formulário (Apêndice A) foi estruturado buscando coletar análises do desempenho do Conselho e da própria entidade na pauta do direito à informação e traçar uma rede social a partir da visão de quais entidades e órgãos atuavam e atuam em maior sintonia com a suas pautas. Anexados ao questionário foram enviados termos de consentimento, que permitem a reprodução das respostas no presente trabalho (Apêndices B e C).

O formulário foi enviado para 58 membros titulares e 29 membros suplentes do Conselho, no período de 4 a 24 de abril de 2017, obtendo o reduzido número de dez respostas. Tais respostas possibilitaram a construção de um segundo sociograma, também por meio da ferramenta yEd Graph Editor, conforme demonstrado a seguir: 
FIGURA 2 - REDE DO CNRH A PARTIR DAS RESPOSTAS DOS CONSELHEIROS AO FORMULÁRIO

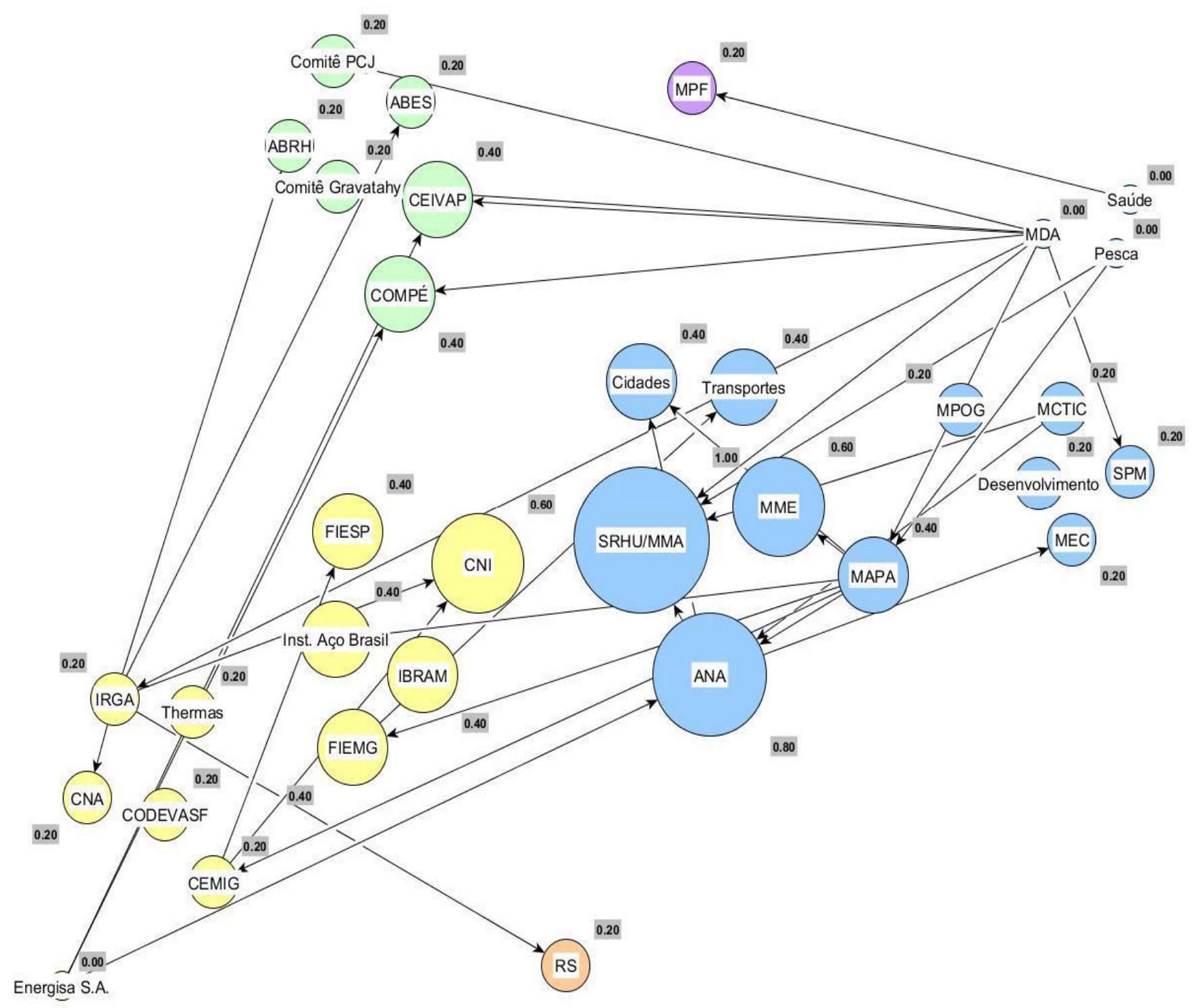

FONTE: O autor (2017).

O gráfico foi desenvolvido a partir das respostas dos conselheiros da ANA, do MCTIC, do Ministério da Pesca e Aquicultura, do Ministério de Agricultura, Pecuária e Abastecimento (Mapa), do Ministério da Saúde, da Secretaria Especial de Agricultura e Desenvolvimento Agrário (antigo Ministério do Desenvolvimento Agrário), da Companhia Energética de Minas Gerais (Cemig), da Federação das Indústrias de Minas Gerais - FIEMG, do Irga e da Energisa S.A. A rede formada ilustra os posicionamentos dos órgãos e entidades que foram mencionados como tendo relações próximas com os membros do Conselho que responderam o formulário.

A totalidade dos atores representados pode ser visualizada pela tabela a seguir: 
MARTINS, J. V. R. O acesso à informação ambiental e a gestão hídrica: uma análise da implementação do sistema nacional...

TABELA 2 - Dados de centralidade referentes à Rede do CNRH a partir das respostas dos Conselheiros ao Formulário

\section{GOVERNO FEDERAL}

1. Secretária Nacional de Recursos Hídricos e Qualidade Ambiental/ Ministério do Meio Ambiente - SNRH/MMA

2. Agência Nacional de Águas - ANA

3. Ministério dos Transportes - Transportes

4. Ministério de Planejamento, Orçamento e Gestão - MPOG

5. Ministério de Minas e Energia - MME

6. Ministério da Saúde - Saúde

7. Ministério da Ciência, Tecnologia, Inovações e Comunicações - MCTIC

8. Ministério da Educação - MEC

9. Ministério da Pesca e Aquicultura - Pesca

10. Ministério do Desenvolvimento, Indústria e Comércio Exterior - Desenvolvimento

11. Ministério das Cidades - Cidades

12. Ministério da Agricultura, Pecuária e Abastecimento - MAPA

13. Secretaria Especial de Agricultura e Desenvolvimento Agrário - Antigo Ministério do Desenvolvimento Agrário - MDA

14. Secretaria Especial de Políticas para as Mulheres - SPM

1. Conselho Estadual de Recursos Hídricos do Rio Grande do Sul - RS

1. Confederação Nacional das Indústrias - CNI

2. Federação das Indústrias de Minas Gerais - FIEMG

3. Instituto Brasília Ambiental - IBRAM

4. Federação das Indústrias do Estado de São Paulo - FIESP 0.40

5. Companhia Energética de Minas Gerais - CEMIG

6. Companhia de Desenvolvimento dos Vales do São Francisco e do Parnaíba - Codevasf

7. Instituto Aço Brasil

Instituto Riograndense do Arroz - IRGA

8. Companhia Thermas do Rio Quente - Thermas

9. Confederação da Agricultura e Pecuária - CNA

10. Energisa S.A.

1. Associação Brasileira de Recursos Hídricos - ABRH

2. Comitê Gravatahy

3. Comitê das Bacias Hidrográficas dos Rios Piracicaba, Capivari e Jundiaí - Comitê PCJ

4. Comitê de Integração da Bacia Hidrográfica do Rio Paraíba do Sul - CEIVAP

5. Comitê das Bacias Hidrográficas dos Afluentes Mineiros dos Rios Pomba e Muriaé COMPÉ

6. Associação Brasileira de engenharia Sanitária e Ambiental - ABES

\section{CONVIDADOS}

1. Ministério Público Federal

FONTE: O autor (2017).

Como na Figura 2, o tamanho dos nós representa sua posição na escala de valores construída a partir do número de menções nas respostas, indo de 0 (nenhuma menção) a 1 (quatro menções). A maior distribuição dos valores e a maior integração representada no gráfico resultam, também, do tipo de pergunta empregado, sem um número taxativo de entidades a serem mencionadas. Assim, embora as relações e aproximações obtidas não representem a 
totalidade das ligações presentes na rede do Conselho, o sociograma obtido permite uma análise inicial de como os atores atuam em relação ao tema do direito à informação e do controle da implementação e funcionamento do sistema de informações.

Novamente, é possível perceber a centralidade da ANA e da SRHU; porém, novos atores ganham destaque, quando comparada a Figura 2 à Figura 1. Destaca-se, também, a centralidade atribuída ao MME e ao Mapa como representantes do Governo Federal, e às entidades da indústria. Além disso, há menção a agentes que não estavam presentes no sociograma anteriormente analisado, como a CNA, a Abes e dois conselhos de bacias hidrográficas (Ceivap e Compé). É interessante notar, também, a articulação presente entre o Ministério da Saúde e o Ministério Público Federal (representado em roxo por não fazer parte do rol de conselheiros), podendo tal articulação representar um outro eixo de participação e atuação diante dos problemas e desafios impostos pela implementação do acesso à informação na gestão hídrica. A mudança no perfil de alguns conselheiros que foram considerados marginais ou, até mesmo, não apareceram nas análises anteriores também pode ser exemplificada pelas respostas das perguntas de auto avaliação referentes à atuação do Conselho e dos membros nas discussões sobre o tema aqui abordado.

Segundo os eixos acima mencionados, foram elaboradas quatro perguntas que buscaram analisar as atuações: 1) do Conselho em relação ao tema do direito de acesso à informação; 2) do Conselho no controle e gerenciamento do SNIRH; 3) da própria entidade na consolidação do direito de acesso à informação como um pilar na gestão hídrica; e 4) da própria entidade na implementação do SNIRH ${ }^{7}$. As respostas possibilitaram avaliações entre "ruim”, "regular”, "satisfatória”, “excelente” e a opção "não se aplica ou não desejo responder”. Houve, ainda, uma quinta pergunta que abria espaço para que outras informações ou comentários fossem feitos.

Com as respostas, pudemos formar os gráficos a seguir:

\footnotetext{
${ }^{7}$ Conforme o Apêndice A - Formulário, as perguntas consistiram em: "Como você avalia a atuação do Conselho Nacional de Recursos Hídricos nas discussões sobre o tema do direito de acesso à informação, enquanto um princípio-base da Política Nacional de Recursos Hídricos?”; "Sobre a atuação do Conselho Nacional de Recursos Hídricos, qual sua avaliação sobre sua atuação como um todo, no controle da efetiva implementação do Sistema Nacional de Informações sobre Recursos Hídricos - SNIRH?”; “Em relação à sua entidade ou órgão, qual o nível de atuação dentro das discussões do CNRH sobre o direito de acesso à informação, no âmbito da gestão de recursos hídricos?"; "Ainda sobre a atuação da sua entidade ou órgão, como você avalia a atuação, dentro do escopo de ação do Conselho Nacional de Recursos Hídricos, no sentido de promover uma análise e um controle do processo de implementação, gestão e funcionamento do Sistema Nacional de Recursos Hídricos?"; "Dentro do Conselho Nacional de Recursos Hídricos, quais, de 3 a 5, órgãos governamentais, entidades e/ou atores atuam em sintonia com a organização que você representa enquanto Conselheiro?”.
} 
MARTINS, J. V. R. O acesso à informação ambiental e a gestão hídrica: uma análise da implementação do sistema nacional...

FIGURA 3 - RESPOSTAS DOS CONSELHEIROS ÀS AVALIAÇÕES PRESENTES NO FORMULÁRIO

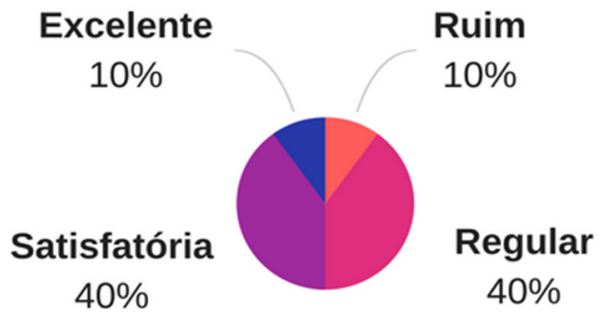

Pergunta 1

\section{Excelente}

$20 \%$

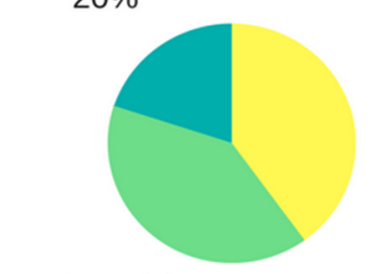

Satisfatória

$40 \%$

Pergunta 3

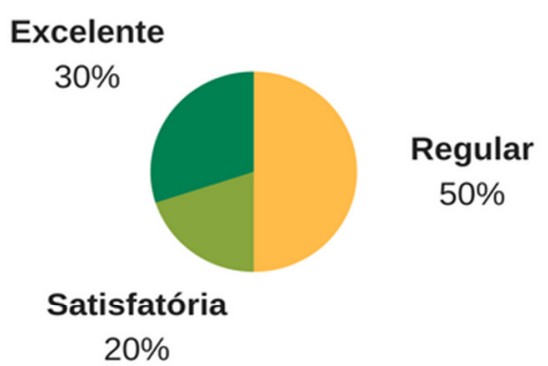

Pergunta 2

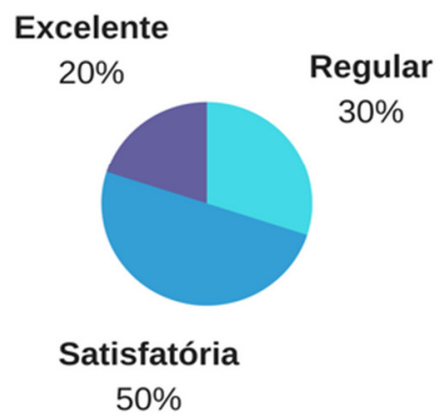

Pergunta 4

FONTE: O autor (2017).

Assim, é possível perceber uma visão crítica, de modo geral, à atuação do Conselho, nos dois eixos de perguntas presentes no questionário, além da indicação de uma necessidade de melhoria na maneira como as próprias entidades trabalham a questão do acesso à informação e o controle do SNIRH.

No último espaço, foram feitos alguns comentários relevantes para a análise aqui proposta. Além do indicativo de que deveria haver maior comprometimento com a Gestão Integrada dos Recursos Hídricos, há um comentário central sobre o próprio SNIRH, aqui transcrito, ambas as observações tendo sido feitas por representantes do Governo Federal:

O SNIRH é ainda pouco conhecido. Não tem interfaces amigáveis para os interessados e público em geral. Fala-se pouco do SNIRH nas reuniões e temáticas do CNRH. De uma forma geral, as informações disponíveis são pouco amigáveis ao público.

Há uma constatação, portanto, da baixa centralidade e prioridade atribuída ao tema nas reuniões do Conselho, algo que também pode ser visto no baixo número de discursos que o envolvem, como percebido no sociograma anterior. Os novos gráficos complementam as 
interpretações anteriores, explicitando como a rede política em estudo apresenta complexidades que devem ser analisadas utilizando uma diversidade de métodos e instrumentos.

\section{CONCLUSÃO}

O Sistema Nacional de Informações sobre Recursos Hídricos (SNIRH) é resultado de um conjunto de esforços e construções nacionais e internacionais nos âmbitos políticos, jurídicos, institucionais, administrativos e participativos. Seja pelas óticas da primazia da ordem democrático-constitucional, pelo reconhecimento internacional dos direitos à liberdade de expressão e ao meio ambiente ou como mecanismo de concretização da democracia participativa, a instituição de um sistema de coleta, organização e distribuição de informações deve ser visto como um avanço.

Ao colocar o Sistema como um de seus instrumentos e construir mecanismos de controle público como o Conselho Nacional de Recursos Hídricos, a Política Nacional de Recursos Hídricos admite a sua importância e a relação entre participação e controle social e o direito à informação. As análises apresentam um parâmetro inicial no debate sobre a efetividade de tais mecanismos e os meios possíveis para uma consolidação e concretização do acesso à informação na gestão hídrica. Alguns pontos foram colocados pela análise teórica e pelos gestores, como a necessidade de fortalecimento da gestão integrada, de compartilhamento e coordenação entre os sistemas de informação e de construção de mecanismos eficazes no acesso e na distribuição dos dados disponíveis.

As redes sociais formadas a partir das análises das atas das reuniões do CNRH e dos formulários veiculados entre os conselheiros permitem uma visualização gráfica de como os diferentes órgãos e entidades se organizam em torno do direito à informação na gestão hídrica. Pontos como a baixa presença do tema nas discussões das reuniões, o alto número de centralidade da Secretaria de Recursos Hídricos do Ministério do Meio Ambiente e do Agência Nacional de Águas e a generalidade de uma posição crítica por parte dos conselheiros sobre a atuação do Conselho na promoção do direito à informação podem ser extraídos dos dados coletados.

O trabalho, portanto, aborda alguns aspectos da relação entre a informação e a gestão hídrica, de acordo com os instrumentos trazidos como recortes da teoria política da democracia participativa, do debate de avaliação e implementação de políticas públicas e da metodologia de redes sociais. Observa-se, no entanto, a necessidade de instrumentos diversos para a abordagem da temática de acordo com as complexidades apresentadas. 
MARTINS, J. V. R. O acesso à informação ambiental e a gestão hídrica: uma análise da implementação do sistema nacional...

\section{REFERÊNCIAS}

ARTIGO 19. O direito do público a estar informado: princípios sobre a legislação de liberdade de informação. 1999. Disponível em: <http://www.article19.org/pdfs/standards/public-right-toknow-portuguese.pdf>. Acesso em: 21 abr. 2017.

AVRITZER, L. (Org.). Experiências nacionais de participação social. Belo Horizonte: Cortez Editora, 2010.

AARHUS, Convention. Convention on Access to Information, Public Participation in DecisionMaking and Access to Justice in Environmental Matters. On-line. Aarhus, Denmark: 1998. Disponível em < http://www.unece.org/fileadmin/DAM/env/pp/documents/cep43e.pdf>. Acesso em: 21 abr. 2017.

AVRITZER, L.; SOUZA, C. H. L. (Org.). Conferências nacionais: atores, dinâmicas participativas e efetividade. 1. ed. Brasília: IPEA, 2013.

BARRETO, R.V. Políticas Públicas e o Desenvolvimento Rural Sustentável no Estado do Ceará. Dissertação (Mestrado Desenvolvimento Rural e Sustentável). Universidade Federal do Ceará, 2004.

BOORMAN, S. A.; WHITE, H. C. Social Structure from Multiple Networks. II. Role Structures. American Journal of Sociology, Chicago, 1976.

BRASIL. Constituição (1988). Constituição: República Federativa do Brasil. Brasília, DF: Senado Federal, $1988 . \quad$ Disponível em: <http://www.planalto.gov.br/ccivil_03/constituicao/constitui\%C3\%A7ao.htm>. Acesso em: 21 abr. 2017.

. Lei no 9.433, de 8 de janeiro de 1997. Lei das Águas. Diário Oficial da União, Brasília, DF, 9 jan. 1997, p. $470 . \quad$ Disponível em: <http://www.planalto.gov.br/ccivil_03/leis/L9433.htm>. Acesso em: 21 abr. 2017.

Lei n. ${ }^{\circ} 11.445$, de 5 de janeiro de 2007. Estabelece diretrizes nacionais para o saneamento básico. . Diário Oficial da União, Brasília, DF, 5 jan. 2007, p. 1. Disponível em: <http://www.planalto.gov.br/ccivil_03/_ato2007-2010/2007/lei/111445.htm >. Acesso em: 21 abr. 2017.

. Lei n. ${ }^{\circ}$ 12.334, de 20 de setembro de 2010. Estabelece a Política Nacional de Segurança de Barragens. Diário Oficial da União, Brasília, DF, 20 set. 2011, p. 1. Disponível em: <http://www.planalto.gov.br/ccivil_03/_ato2007-2010/2010/lei/112334.htm>. Acesso em: 21 abr. 2017.

. Lei $\mathrm{n}^{\circ} 12.527$, de 18 de novembro de 2011. Lei de Acesso à Informação. Diário Oficial da União, Brasília, DF, 18 nov. 2011, p. 1. Disponível em: <http://www.planalto.gov.br/ccivil_03/_ato2011-2014/2011/lei/112527.htm>. Acesso em: 21 abr. 2017. 
Conselho Nacional de Recursos Hídricos. Portaria no 437, de 8 de novembro de 2013. Conselho Nacional de Recursos Hídricos, Brasília, DF, 8 nov. 2013. Disponível em: $<$ http://www.cnrh.gov.br/index.php?option=com_content\&view $=$ article\&id=7>. Acesso em: 21 abr. 2017.

Conselho Nacional de Recursos Hídricos. Resolução no ${ }^{13}$, de 25 de setembro de 2000. Conselho Nacional de Recursos Hídricos, Brasília, DF, 25 set. 2000. Disponível em: $<$ http://www.cnrh.gov.br/index.php?option=com_docman\&task=doc_download\&gid=59>. Acesso em: 21 abr. 2017.

CEDRAZ, A. A gestão de recursos hídricos e o sistema federativo. Plenarium, Brasília, n. 3, p. 118-124, set. 2006.

CONSELHO INTERNACIONAL DE ARQUIVOS. Princípios de Acesso aos Arquivos: versão preliminar. 2011.2 Disponível em: <http://www.ica.org/sites/default/files/ICA\%20Standards_Access_principles_PO.pdf>. Acesso em: 21 abr. 2017.

EMIRBAYER, M.; GOODWIN, J. Network Analysis, Culture and the Problem of Agency. American Journal of Sociology, Chicago, v. 99, n. 6, p. 1411-1454, 1994.

KATZ, N. et al. Network Theory and Small Groups. Small Group Research, v. 35, n. 3, p. 307332. New York: Sage Publications, 2004.

MARQUES, E. C. Redes sociais, instituições e atores políticos no governo da cidade de São Paulo. São Paulo: Annablume, 2003.

MASSARDIER, G. Redes de política pública. In: SARAIVA, E; FERRAREZI, E. (Org.). Políticas Públicas. Brasília: ENAP, 2006. p. 167-185

MENDEL, T. Liberdade de informação: um estudo de direito comparado. 2. ed. Brasília: Unesco, 2009.

ORGANIZAÇÃO DOS ESTADOS AMERICANOS. Comissão Interamericana de Direitos Humanos. Declaração de Princípios sobre Liberdade de Expressão. 2000. Disponível em: $<$ https://www.cidh.oas.org/basicos/portugues/s.Convencao.Libertade.de.Expressao.htm>.

Acesso em: 21 abr. 2017.

OLIVEIRA, G.; DINARTE, P.; SILVA, R. O direito de acesso à informação ambiental como potencializador da e-democracia: o papel do Governo Aberto na conscientização ambiental a partir do desenvolvimento de plataformas e aplicativos. Revista Democracia Digital e Governo Eletrônico, Florianópolis, n. 11, p. 138-162, 2014.

ORGANIZAÇÃO DAS NAÇÕES UNIDAS. Declaração de Estocolmo sobre o Ambiente Humano (Declaração de Estocolmo), adotada de 5 a 16 de junho de 1972. Online. Disponível em <http://www.silex.com.br/leis/normas/estocolmo.htm>. Acesso em: 21 abr. 2017

Declaração do Rio de Janeiro sobre Meio Ambiente e Desenvolvimento (Declaração do Rio), adotada de 3 a 14 de junho de 1992. Online. Disponível em <http://www.onu.org.br/rio20/img/2012/01/rio92.pdf>. Acesso em: 21 abr. 2017. 
MARTINS, J. V. R. O acesso à informação ambiental e a gestão hídrica: uma análise da implementação do sistema nacional...

OPEN GOVERNMENT PARTNERSHIP. Open Government Declaration. 2. ed. 2016. Disponível em: <http://www.opengovpartnership.org/sites/default/files/091116_OGP_Booklet_digital.pdf>. Acesso em: 21 abr. 2017.

PORTO, M. F. A.; PORTO, R. L. L. Gestão de bacias hidrográficas. Revista Estudos Avançados, São Paulo, v. 33, n. 63, p. 43-60, mai./ago. 2008.

ROMANO, E.; ROMANO, P. A.; FEITOSA, V. M. N. Gestão descentralizada e participativa dos recursos hídricos e a mineração: riscos e oportunidades. In: DOMINGUES, A. F.; BOSON, P. H. G.; ALÍPAZ, S. (Org.). Agência Nacional de Águas: a gestão dos recursos hídricos e a mineração. Brasília: ANA, 2006. p. 51-67.

ROVER, A. J. A democracia digital possível. Revista Seqüência, n. 52, p. 85-104, jul. 2006.

SCOTT, J. Social Network Analysis: a Handbook. 2. ed. Londres: Sage Publications, 2000

VAZ, J. C.; RIBEIRO, M. M.; MATHEUS, R. Dados governamentais abertos e seus impactos sobre os conceitos e práticas de transparência no brasil. Cadernos PPG-AU/UFBA, Salvador, v. 9, 2010.

VIANA, M. B.; PINHEIRO, A. Instrumento de gestão das águas. Brasília: Centro de Estudos e Debates Estratégicos da Câmara dos Deputados, 2015. Série Estudos Estratégicos, n. 6.

WASSERMAN, S.; FAUST, K. Social Network Analysis: Methods and Applications. Cambridge: Cambridge University Press, 1994.

WELlmAN, B. Network Analysis: Some Basic Principles. Sociological Theory, São Francisco, v. 1, 1983.

YWORKS. $y E d$ Graph Editor, versão 3.17.1. Disponível em: <https://www.yworks.com/products/yed>. Acesso em: 21 abr. 2017.

\section{APÊNDICE A - FORMULÁRIO}

Avaliação do Sistema Nacional de Recursos Hídricos segundo as perspectivas dos conselheiros do Conselho Nacional de Recursos Hídricos

Perguntas:

1. Endereço de e-mail:

Resposta curta aberta.

2. Qual entidade ou órgão você representa no Conselho Nacional de Recursos Hídricos? Resposta curta aberta.

3. Como você avalia a atuação do Conselho Nacional de Recursos Hídricos nas discussões sobre o tema do direito de acesso à informação, enquanto um princípio-base da Política Nacional de Recursos Hídricos? 
Resposta de múltipla escolha, opções: a) ruim, b) regular, c) satisfatória, d) excelente, e) não se aplica ou não desejo responder.

4. Sobre a atuação do Conselho Nacional de Recursos Hídricos, qual a sua avaliação sobre sua atuação, como um todo, no controle da efetiva implementação do Sistema Nacional de Informações sobre Recursos Hídricos - SNIRH?

Resposta de múltipla escolha, opções: a) ruim, b) regular, c) satisfatória, d) excelente, e) não se aplica ou não desejo responder.

5. Em relação à sua entidade ou órgão, qual o nível de atuação dentro das discussões do CNRH sobre o direito de acesso à informação, no âmbito da gestão de recursos hídricos?

Resposta de múltipla escolha, opções: a) ruim, b) regular, c) satisfatória, d) excelente, e) não se aplica ou não desejo responder.

6. Ainda sobre a atuação da sua entidade ou órgão, como você avalia a atuação, dentro do escopo de ação do Conselho Nacional de Recursos Hídricos, no sentido de promover uma análise e um controle do processo de implementação, gestão e funcionamento do Sistema Nacional de Informações sobre Recursos Hídricos?

Resposta de múltipla escolha, opções: a) ruim, b) regular, c) satisfatória, d) excelente, e) não se aplica ou não desejo responder.

7. Dentro do Conselho Nacional de Recursos Hídricos, quais, de 3 a 5 órgãos governamentais, entidades e/ou atores atuam em sintonia com a organização que você representa enquanto Conselheiro? A pergunta busca entender a rede formada dentro do âmbito do Conselho Nacional de Recursos Hídricos. Embora a margem de 3 a 5 atores seja mencionada, a pergunta é estruturada para permitir inúmeras citações.

Resposta aberta longa.

8. Gostaria de adicionar alguma informação ou comentário sobre os temas tratados no presente questionário?

Resposta aberta longa.

\section{APÊNDICE B - TERMO DE CONSENTIMENTO}

\section{TERMO DE CONSENTIMENTO}

O presente formulário faz parte da pesquisa de iniciação científica do estudante JOÃO VITOR RODRIGUES MARTINS na Faculdade de Direito da Universidade de Brasília, feita sob a orientação da Profa. Dra. ANA CLÁUDIA FARRANHA, segundo Edital PROIC/PIBIC 2016/2017.

O objetivo geral da pesquisa é analisar o processo de implementação e formulação do Sistema Nacional de Informações Sobre Recursos Hídricos - SNIRH, conforme instituído pela Lei ${ }^{\circ}$ 9.433, de 8 de janeiro de 1997, enquanto política pública de acesso à informação no âmbito da gestão de recursos hídricos. O formulário elaborado busca conhecer, em termos rápidos, as avaliações feitas pelos Conselheiros sobre as diferentes atuações no âmbito do CNRH que interessam o trabalho. O formulário é estruturado em perguntas de avaliação geral sobre as atuações do $\mathrm{CNRH}$, de uma forma conjunta, e das entidades e órgãos representadas pelos conselheiros. Além disso, há um último apontamento que busca entender a rede de atores formada em torno da questão de acesso à informação na gestão de Recursos Hídricos.

Por se tratar da investigação acadêmica, entende-se que os nomes das entidades, órgãos e organizações representadas pelos Conselheiros poderão ser divulgados ao longo do texto do relatório de pesquisa. No entanto, o(a) entrevistado(a) poderá exigir anonimato ao revelar determinada informação ou negar-se a responder qualquer pergunta se isso lhe faz sentir-se desconfortável. 
MARTINS, J. V. R. O acesso à informação ambiental e a gestão hídrica: uma análise da implementação do sistema nacional...

As respostas desse formulário são de uso exclusivo do pesquisador e os resultados poderão ser veiculados através do seu trabalho de iniciação científica e em artigos científicos, revistas especializadas ou encontros científicos. Qualquer observação à entrevista ou ao trabalho como um todo poderá ser feito ao pesquisador por meio do email: joaovitormartins2@gmail.com ou pelo telefone (61) 9-9844-0729.

Agradeço a gentileza de ceder o seu tempo para esse formulário.

\section{APENNICE C - ANEXO DO TERMO DE CONSENTIMENTO COM AS ASSINATURAS}

Declaro para os devidos fins que estou ciente do teor da pesquisa e concordo em participar de forma livre e esclarecida.

Nome:

Local e Data:

Assinatura: 